\title{
Intraoperative conversion from video-assisted thoracoscopic surgery lobectomy to open thoracotomy: A study of causes and implications
}

\author{
Varun Puri, MD, MSCI, Aalok Patel, BS, Kaustav Majumder, MBBS, Jennifer M. Bell, BSN, \\ Traves D. Crabtree, MD, A. Sasha Krupnick, MD, Daniel Kreisel, MD, PhD, Stephen R. Broderick, MD, \\ G. Alexander Patterson, MD, and Bryan F. Meyers, MD, MPH
}

Objective: To study causes and implications of intraoperative conversion to thoracotomy during video-assisted thoracoscopic surgery (VATS) lobectomy.

Methods: We performed an institutional review of patients undergoing lobectomy for known or suspected lung cancer with root cause analysis of every conversion from VATS to open thoracotomy.

Results: Between 2004 and 2012, 1227 patients underwent lobectomy. Of these, 517 procedures $(42 \%)$ were completed via VATS, 87 procedures $(7 \%)$ were converted to open procedures, and 623 procedures $(51 \%)$ were performed via planned thoracotomy. Patients undergoing thoracotomy were younger and had a higher incidence of prior lung cancers. Planned thoracotomy and conversion group patients had higher clinical $\mathrm{T}$ stage than patients in the VATS group, whereas the planned thoracotomy group had higher pathologic stage than patients in the other groups. Postoperative complications were more frequent in patients in the conversion group (46\%) than in the VATS group $(23 \% ; P<.001)$, but similar to the open group $(42 \% ; P=.56)$. Validating a previous classification of causes for conversion, 22 out of 87 conversions $(25 \%)$ were due to vascular causes, 56 conversions $(64 \%)$ were for anatomy (eg, adhesions or tumor size), and 8 conversions $(9 \%)$ were the result of lymph nodes. No specific imaging variables predicted conversion. Within the conversion groups, emergent (20 out of $87 ; 23 \%$ ) and planned (67 out of $87 ; 77 \%$ ) conversion groups were similar in patient and tumor characteristics and incidence of perioperative morbidity. The conversion rate for VATS lobectomy dropped from 21 out of 74 $(28 \%)$, to 29 out of $194(15 \%)$, to 37 out of $336(11 \%)(P<.001)$ over 3 -year intervals. Over the same periods, the proportion of operations started via VATS increased significantly.

Conclusions: With increasing experience, a higher proportion of lobectomy operations can be completed thoracoscopically. VATS should be strongly considered as the initial approach for the majority of patients undergoing lobectomy. (J Thorac Cardiovasc Surg 2015;149:55-62)

See related commentary on pages 62-3.

\section{Supplemental material is available online.}

\footnotetext{
From the Department of Surgery, Washington University School of Medicine, St Louis, Mo.

Varun Puri is supported by National Institutes of Health grant Nos. K07CA178120 and K12CA167540-02 (Paul Calabresi Award).

Disclosures: Bryan F. Meyers reports consulting fees from Ethicon Endosurgery and Varian Medical Systems. The other authors have nothing to disclose with regard to commercial support.

Read at the 94th Annual Meeting of The American Association for Thoracic Surgery, Toronto, Ontario, Canada, April 26-30, 2014.

Received for publication April 9, 2014; revisions received Aug 6, 2014; accepted for publication Aug 20, 2014; available ahead of print Oct 16, 2014.

Address for reprints: Varun Puri, MD, MSCI, 3108 Queeny Tower, Barnes Jewish Hospital, One Barnes Jewish Hospital Plaza, St Louis, MO 63110 (E-mail: puriv@wudosis.wustl.edu).

$0022-5223 / \$ 36.00$

Copyright (c) 2015 by The American Association for Thoracic Surgery

http://dx.doi.org/10.1016/j.jtcvs.2014.08.074
}

Surgical resection via lobectomy and systematic mediastinal lymph node assessment is the gold standard for treatment of early stage non-small cell lung cancer (NSCLC). The feasibility, safety, and oncologic efficacy of video-assisted thoracoscopic surgery (VATS) lobectomy have been established over the past 2 decades via large institutional series ${ }^{1,2}$ as well as multicenter trials. ${ }^{3}$ Despite the favorable evidence, registry data as well as data from the Society of Thoracic Surgeons (STS) general thoracic database show that only $30 \%$ to $40 \%$ of anatomic lung resections are performed utilizing VATS.,

Technical barriers, including a potential higher risk of intraoperative complications and perceptions about unplanned conversions to thoracotomy, are important issues preventing more widespread acceptance of VATS lobectomy. The incidence of intraoperative conversion to an open approach ranges from $5 \%$ to $23 \%$ with nearly half the conversions being performed emergently. ${ }^{6-8}$ Retrospective series describing conversions show conflicting evidence with some centers reporting greater perioperative morbidity compared with successful VATS 


\section{Abbreviations and Acronyms \\ NSCLC $=$ non-small cell lung cancer \\ STS = Society of Thoracic Surgeons \\ VATS $=$ video-assisted thoracoscopic surgery}

completion $^{6}$ with others showing equivalent outcomes. ${ }^{9}$ Few reports compare unplanned conversions with planned thoracotomy for lobectomy. ${ }^{6}$

Preoperative patient-related variables have been studied for association with the likelihood of conversion and computed tomography scan lymph node calcification score found to be a potential predictor. ${ }^{6}$ The role of surgeon/ institutional experience in conversion, however, remains inadequately understood. Additionally, the effect of conversion on immediate and delayed outcomes is debatable.

Our objective was to study causes of intraoperative conversions to thoracotomy during VATS lobectomy using and validating an existing classification system. ${ }^{8}$ We also assessed short- and long-term implications of conversion with respect to cases completed using VATS and those undergoing planned thoracotomy.

\section{PATIENTS AND METHODS}

With approval from the institutional review board at Washington University School of Medicine, a single-center, retrospective review of our database was performed to identify patients who had undergone lobectomy for known or suspected lung cancer between December 2004 and December 2012. We chose a start date of 2004 for the study because we initially started offering VATS lobectomy in 2004. Additionally, electronic patient records have been reliably available for review since that time. Patients who underwent a complete anatomic lobectomy with individual division of hilar bronchovascular structures were included in the study cohort. Patients undergoing wedge resection, segmentectomy, bilobectomy, or pneumonectomy were excluded, as were any patients who underwent lung transplantation.

Each patient was classified as having undergone a VATS lobectomy, open thoracotomy, or intraoperative unplanned conversion from VATS to open operation for lobectomy by an independent chart review by 2 observers (K.M. and V.P.). Cases with inconsistent classification by the 2 observers were resolved by joint review by K.M., V.P., and J.B. VATS lobectomy was defined according to Cancer and Leukemia Group B 39802 trial criteria. ${ }^{3}$ Briefly, the technique mandated no rib spreading; a maximum incision length of $8 \mathrm{~cm}$ for removal of the lobectomy specimen; individual dissection of the vein, arteries, and airway; and standard lymph node sampling or dissection (identical to an open thoracotomy). Cases where a planned VATS operation was intraoperatively abandoned in favor of an open thoracotomy with rib spreading were classified as conversions. Each conversion was studied in detail by 2 observers (K.M. and V.P.) in a root cause analysis ${ }^{10}$ and classified using the previously described VALT system as either vascular, anatomy (related), lymph node (related), or technical (equipment failure). ${ }^{8}$

We utilized a prospectively maintained database to glean information about patient demographics, diagnosis, preoperative workup, operation, perioperative course, and outcomes. Missing data were obtained by a review of patient charts. Perioperative events were defined per STS data collection guidelines (Table E1) Follow-up data were obtained from clinic notes and supplemented by querying the social security death index to determine survival.
Data were managed using Excel (version 2010, Microsoft Corp, Redmond, Wash) and analyzed using SPSS version 22.0 for Windows (IMB-SPSS Inc, Armonk, NY). Descriptive statistics were expressed as mean \pm standard deviation unless otherwise specified. Categorical data were expressed as counts and proportions. Comparisons were done with 2-tailed $t$ tests for means of normally distributed continuous variables. Differences among the categorical data were analyzed with either Fisher exact test or $\chi^{2}$ comparison. We generated Kaplan-Meier (product limit) survival plots, and survival comparisons between groups of patients were completed using the Mantel-Haenszel log rank test. After an initial exploratory comparison between the VATS, open, and conversion groups, logistic regression models were fitted to assess the influence of preoperative variables on the likelihood of conversion. The influence of increasing institutional experience with VATS lobectomy was studied separately by dividing the population into 3 -year intervals. A secondary analysis of emergent and nonemergent conversions was also carried out. Emergent conversions were defined as those dictated by significant bleeding or airway injury, whereas nonemergent conversions were related to lack of progress in the operation. For the purpose of this study, in keeping with STS definitions, conditions signifying major perioperative morbidity are summarized in Table E1.

\section{RESULTS}

Between 2004 and 2012, 1227 patients underwent lobectomy for known or suspected lung cancer at our institution. Of these, 517 procedures $(42 \%)$ were completed via VATS, 87 procedures $(7 \%)$ were converted to open operation, and 623 procedures $(51 \%)$ were performed via planned thoracotomy. Patients undergoing thoracotomy were younger and had a higher incidence of prior lung cancers. (Table 1) Patients undergoing successful VATS lobectomy were less likely to be men, current smokers, or have undergone prior cardiothoracic surgery. Planned thoracotomy and conversion group patients had higher clinical T stage than patients in the VATS group (Table 1), whereas patients in the planned thoracotomy group had higher clinical $\mathrm{N}$ stage than patients in the other 2 groups. There was no difference in the prevalence of intrathoracic granulomatous disease, including lymph node calcifications, between the groups. Patients undergoing successful VATS had a somewhat higher forced expiratory volume in 1 second percent predicted that those undergoing thoracotomy. Patients in the planned thoracotomy group had higher pathologic stage than patients in the other groups (Table 1).

Postoperative STS database-defined complications were more frequent in the conversion group, (40 out of 87; $46 \%)$ than in the VATS group (119 out of $517 ; 23 \%$ ) $(P<.001)$, but similar to the open group (264 out of 623 ; $42 \%)(P=.56)$. The higher incidence of perioperative morbidity in the 2 open groups was largely related to greater incidence of atelectasis, pneumonia, arrhythmias, and respiratory failure (Table 2). The length of stay was also longer if a patient underwent a planned or unplanned thoracotomy (Table 2). Surgical mortality was similarly low across the groups (thoracotomy 5 out of 623 [0.8\%], VATS 0 out of $517[0 \%]$, and conversion 1 out of 87 $[1 \%] ; P=.1)$. 
TABLE 1. Preoperative variables for the entire cohort of patients undergoing lobectomy $(N=1227)$

\begin{tabular}{|c|c|c|c|c|}
\hline Variable & Thoracotomy only $(n=623)$ & VATS only $(n=517)$ & $\begin{array}{l}\text { VATS conversion to } \\
\text { thoracotomy }(n=87)\end{array}$ & $P$ value \\
\hline Mean age, $y$ & $62.4 \pm 12.3$ & $64.8 \pm 10.9$ & $63.9 \pm 10.4$ & $.002 *$ \\
\hline Male gender & $321(52)$ & $223(43)$ & $47(54)$ & .010 \\
\hline White & $553(88)$ & $444(86)$ & $73(84)$ & .079 \\
\hline Current smoker & $202(32)$ & $131(25)$ & $26(30)$ & .001 \\
\hline Prior lung cancer & $54(9)$ & $28(5)$ & $10(12)$ & .039 \\
\hline Mean body mass index & $26.8 \pm 6.2$ & $27.6 \pm 6.9$ & $27.7 \pm 5.8$ & .082 \\
\hline Hypertension & $306(49)$ & $300(58)$ & $45(52)$ & .011 \\
\hline Granulomatous disease on CT & $154(25)$ & $138(27)$ & $23(26)$ & .739 \\
\hline Prior cardiothoracic surgery & $87(14)$ & $42(8)$ & $13(15)$ & .005 \\
\hline Mean $\mathrm{FEV}_{1}$ percent predicted $\dagger$ & $0.79 \pm 0.20$ & $0.83 \pm 0.18$ & $0.80 \pm 0.19$ & $.002 \ddagger$ \\
\hline Mean DLCO percent predicted $\S$ & $0.73 \pm 0.23$ & $0.74 \pm 0.23$ & $0.69 \pm 0.20$ & .274 \\
\hline Clinical stage & & & & $<.0001$ \\
\hline I & $319(57)$ & $330(75.2)$ & $52(69.3)$ & \\
\hline II & $91(16.1)$ & $42(9.6)$ & $6(8)$ & \\
\hline III & $103(18.3)$ & $27(6.2)$ & $12(16)$ & \\
\hline IV & $47(8.3)$ & $35(7.9)$ & $5(6.7)$ & \\
\hline $\mathrm{X}$ & $2(0.3)$ & $5(1.1)$ & 0 & \\
\hline Clinical tumor stage & & & & $<.0001$ \\
\hline $\mathrm{T} 1$ & $225(40)$ & $306(69.7)$ & $45(60)$ & \\
\hline $\mathrm{T} 2$ & $236(42)$ & $102(23.3)$ & $21(28)$ & \\
\hline $\mathrm{T} 3$ & $55(9.9)$ & $21(4.8)$ & $3(4)$ & \\
\hline $\mathrm{T} 4$ & $44(7.8)$ & $5(1.1)$ & $6(8)$ & \\
\hline $\mathrm{TX}$ & $2(0.3)$ & $5(1.1)$ & 0 & \\
\hline Clinical nodal stage & & & & $<.0001$ \\
\hline No & $400(71.2)$ & $381(86.8)$ & $64(85.4)$ & \\
\hline N1 & $72(12.8)$ & $28(6.4)$ & $4(5.3)$ & \\
\hline $\mathrm{N} 2$ & $87(15.5)$ & $26(5.9)$ & $6(8)$ & \\
\hline N3 & $3(0.5)$ & $4(0.9)$ & $1(1.3)$ & \\
\hline Pathologic stage & & & & $<.0001$ \\
\hline 0 & $15(2.7)$ & $1(0.2)$ & 0 & \\
\hline I & $300(53.4)$ & $315(71.8)$ & $49(66.2)$ & \\
\hline II & $126(22.4)$ & $69(15.7)$ & $16(21.6)$ & \\
\hline III & $100(17.8)$ & $45(10.3)$ & $8(10.8)$ & \\
\hline IV & $19(3.4)$ & $9(2)$ & $1(1.4)$ & \\
\hline $\mathrm{X}$ & $2(0.3)$ & 0 & 0 & \\
\hline
\end{tabular}

Values are presented as mean \pm standard deviation or n (\%). VATS, Video-assisted thoracoscopic surgery; $C T$, computed tomography; $F E V_{l}$, forced expiratory volume in 1 second; $D L C O$, diffusing capacity of the lung for carbon monoxide. *Post-hoc testing revealed statistical difference in age between patients undergoing thoracotomy only and VATS only; $P=.001$. $\dagger$ Data available in 1160 patients. $¥$ Post-hoc testing revealed statistical difference in FEV ${ }_{1} \%$ between patients undergoing thoracotomy only and VATS only; $P=.001 . \S$ Data available in 1025 patients.

Validating a previous classification of causes for conversion, 22 out of $87(25 \%)$ were due to vascular causes, $56(64 \%)$ were for anatomy (ie, adhesions or tumor size), 8 $(9 \%)$ were for lymph nodes, and $1(1 \%)$ was related to a technical failure of equipment. Of 22 conversion due to vascular causes, 15 were related to pulmonary artery injury or subadventitial hematoma, 6 were due to pulmonary venous laceration, and 1 was due to azygous vein injury. Of the 56 operations converted due to anatomy, only 4 were due to tumor size alone (mean size, $6 \mathrm{~cm}$ ), whereas the remaining were related to intrathoracic adhesions, either malignant or inflammatory in nature. In a logistic regression model, only male gender was associated with an elevated risk of unplanned conversion (odds ratio, 1.78; 95\% confidence interval, 1.02-3.11). No other specific preoperative patient-related or imaging variables predicted the likelihood of conversion (Table 3 ). Within the conversions, emergent (20 out of $87 ; 23 \%$ ) and nonemergent (67 out of $87 ; 77 \%$ ) conversion groups were similar in patient and tumor characteristics and incidence of perioperative morbidity (Table E2).

Intraoperative blood transfusion data were reliably available for patients undergoing operation between 2008 and $2012(\mathrm{n}=754)$. The rate of transfusion was lower for those undergoing successful VATS (6 out of $464 ; 1.3 \%$ ) than patients undergoing conversion (11 out of 66 ; $16.7 \%$ ) or planned thoracotomy (23 out of $224 ; 10.3 \%$ ) $(P<.001)$. Patients undergoing emergent conversions 
TABLE 2. Perioperative outcomes in the entire cohort of patients undergoing lobectomy $(N=1227)$

\begin{tabular}{|c|c|c|c|c|}
\hline Variable & Thoracotomy only $(n=623)$ & VATS only $(n=517)$ & $\begin{array}{l}\text { VATS conversion to } \\
\text { thoracotomy }(n=87)\end{array}$ & $P$ value \\
\hline Mean length of stay, $d$ & $7.5 \pm 7.2$ & $4.6 \pm 4.7$ & $7.6 \pm 7.4$ & $<.0001^{*}$ \\
\hline Any postoperative complication & $264(42)$ & $119(23)$ & $40(46)$ & $<.0001$ \\
\hline Pneumonia & $48(8)$ & $20(4)$ & $11(13)$ & .002 \\
\hline Empyema & $2(0.3)$ & $3(0.6)$ & 0 & .653 \\
\hline Arrhythmia & $97(16)$ & $52(10)$ & $16(18)$ & .009 \\
\hline Atelectasis & $27(4)$ & $5(1)$ & $7(8)$ & $<.0001$ \\
\hline Air leak $>5 \mathrm{~d}$ & $39(6)$ & $21(4)$ & $2(2)$ & .115 \\
\hline Pulmonary embolus & $3(0.5)$ & $1(0.2)$ & $2(2)$ & .034 \\
\hline Respiratory failure & $29(5)$ & $1(0.2)$ & $7(8)$ & $<.0001$ \\
\hline Reoperation for bleeding & $7(1)$ & $3(0.6)$ & $1(1)$ & .605 \\
\hline Myocardial infarction & $2(0.3)$ & $1(0.2)$ & 0 & .811 \\
\hline Cerebrovascular accident & $3(0.5)$ & $2(0.4)$ & $2(2)$ & .083 \\
\hline Wound infection & $6(1)$ & 0 & 0 & .054 \\
\hline Operative mortality & $5(0.8)$ & 0 & $1(1)$ & .10 \\
\hline Pathologic upstaging $\dagger$ & 105 (19) & $72(16)$ & $12(16)$ & .610 \\
\hline
\end{tabular}

Values are presented as mean \pm standard deviation or $\mathrm{n}(\%)$. VATS, Video-assisted thoracoscopic surgery. *Post-hoc testing noted statistical difference in length of stay between patients undergoing thoracotomy only and VATS only, and between VATS only and VATS conversion to thoracotomy. $\dagger$ Pathologic upstaging data in 1075 patients.

were more likely to receive intraoperative blood transfusion (9 out of $19 ; 47.4 \%$ ) than those undergoing nonemergent conversion (2 out of $47 ; 4.3 \% ; P<.001$ ).

During the study period, the conversion rate for VATS lobectomy dropped from 21 out of $74(28 \%)$, to 29 out of $194(15 \%)$, to 37 out of $336(11 \%)(P<.001)$ over 3 -year intervals (Figure 1, $A$ ). Over the same time periods, the proportion of operations started VATS increased from 74 out of $473(16 \%)$, to 194 out of $311(62 \%)$, to 336 out of $443(76 \%)(P<.001)$ (Figure $1, B)$. In a multivariate Cox proportional hazard model evaluating patients with pathologic stage I disease, only increasing age, male gender, current smoking status, and lower carbon monoxide diffusing capacity percent predicted were associated with elevated risk of long-term mortality. Intraoperative conversion was not associated with greater hazard of long-term mortality (Table 4).

\section{DISCUSSION}

The main findings of our study are that with increasing experience a greater proportion of lobectomy operations can be performed via VATS and an unplanned conversion to an open approach does not carry any significant elevated risk over a planned open thoracotomy. Although conversions may be hard to predict, only a minority of conversions are emergent, and even those operations are not associated with an elevated risk of morbidity or mortality over nonemergent conversions or planned thoracotomy operations.

VATS lobectomy has consistently been shown to be equivalent or superior to conventional open lobectomy for objective perioperative outcomes. Several institutional series have demonstrated a lower incidence of pulmonary complications, transfusion requirement, and arrhythmias in propensity-matched populations of VATS patients compared with open operations. ${ }^{2,11,12}$ VATS lobectomy has also been found to be less morbid in elderly patients and those with limited pulmonary function. ${ }^{11,13}$ These findings have been reconfirmed in a large STS database analysis that compared matched groups of patients undergoing VATS or open lobectomy and found a significantly lower incidence $(24 \%$ vs $35 \%)$ of complications in the VATS group. ${ }^{4}$

TABLE 3. Logistic regression analysis for predictors of conversion in patients whose procedure started as video-assisted thoracoscopic surgery $(\mathbf{n}=\mathbf{6 0 4})$

\begin{tabular}{lcc}
\hline \multicolumn{1}{c}{ Variable } & Odds ratio & 95\% Confidence interval \\
\hline Age & 0.985 & $0.957-1.013$ \\
Body mass index & 1.001 & $0.962-1.043$ \\
Male gender & 1.78 & $1.015-3.110$ \\
Granulomatous disease on CT scan & 0.940 & .289 \\
Clinical stage N1 & 1.038 & .947 \\
Prior lung cancer & 2.347 & $0.484-1.824$ \\
Prior cardiothoracic surgery & 1.567 & $0.942-5.848$ \\
FEV ${ }_{1}$ percent predicted & 1.305 & .043 \\
DLCO percent predicted & 0.435 & $.9510-4.030$ \\
\hline
\end{tabular}

$C T$, Computed tomography; $F E V_{1}$, forced expiratory volume in 1 second; $D L C O$, diffusing capacity of the lung for carbon monoxide. 


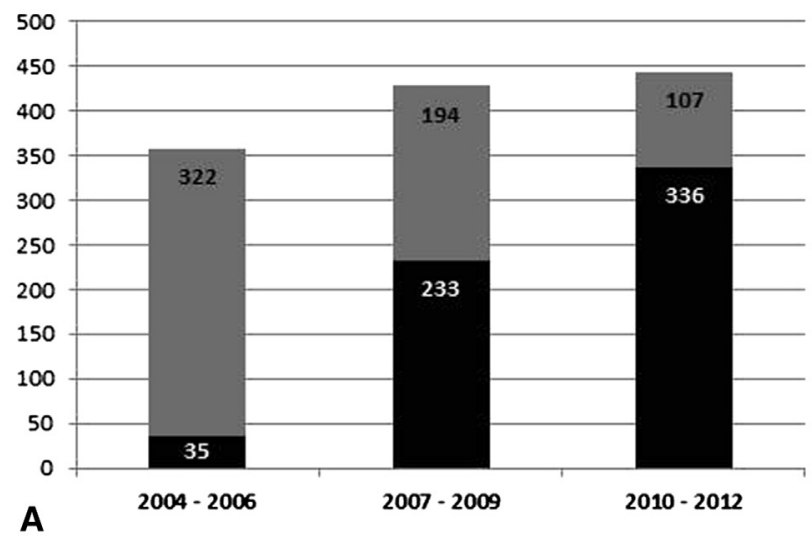

\section{Dlanned Thoracotomy \\ - Attempted VATS}

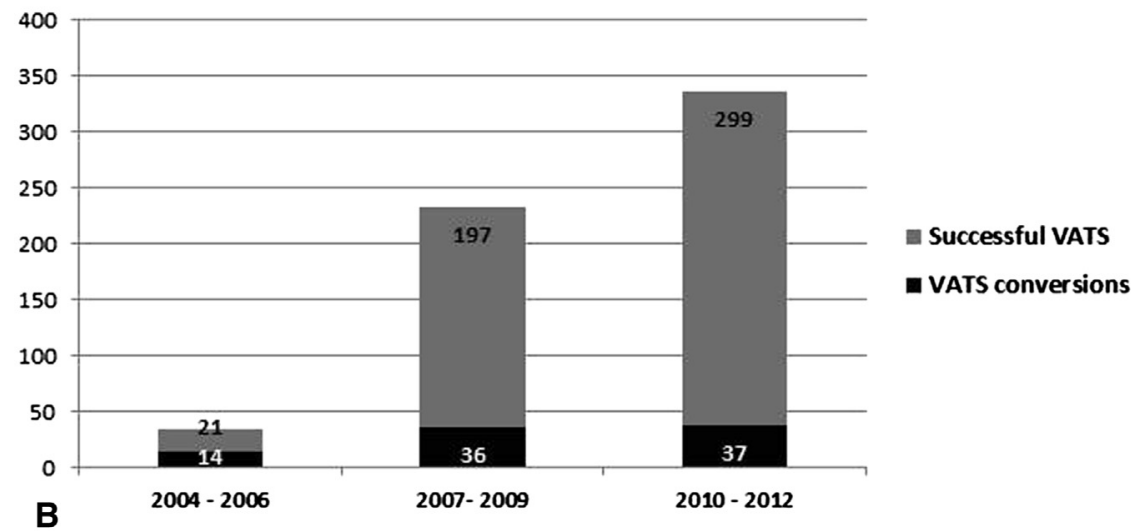

FIGURE 1. A, Distribution of attempted video-assisted thoracoscopic surgery (VATS) versus planned thoracotomies over 3-year intervals. B, Distribution of successful VATS versus VATS conversions over 3-year intervals.

Meta-analyses have confirmed these results. ${ }^{14,15}$ Our findings regarding perioperative complications are quite similar. Despite the aforementioned benefits, and the likely overall cost savings to the health care system, the penetrance of VATS lobectomy for stage I NSCLC remains below 29\% nationally (personal communication, National Cancer Database, 2006-2010 statistics).
In the face of this evidence, it is likely that inadequate exposure to, and concerns about, intraoperative complications, including conversion, prevent a wider acceptance of VATS lobectomy. Indeed, a study of $>13,000$ patients from the Nationwide Inpatient Sample database ${ }^{16}$ found that patients who underwent VATS lobectomy were 1.6 times more likely to have intraoperative complications

TABLE 4. Cox regression analysis studying factors associated with long-term mortality in patients with pathologic stage I non-small cell lung cancer $(\mathbf{n}=\mathbf{5 5 8})$

\begin{tabular}{lccc}
\hline \multicolumn{1}{c}{ Variable } & Hazard ratio & 95\% Confidence interval & \multicolumn{1}{c}{$\boldsymbol{P}$ value } \\
\hline Age & 1.058 & $1.039-1.078$ & $<.0001$ \\
Body mass index & 0.979 & $0.946-1.013$ & .216 \\
Female gender & 0.684 & $0.494-0.946$ & .021 \\
White race & 1.019 & $0.588-1.767$ & .946 \\
Prior lung cancer & 1.348 & $0.699-2.597$ & .391 \\
Current smoker & 1.535 & $1.081-2.182$ & .019 \\
Hypertension & 1.153 & $0.816-1.629$ & \\
Study group & & & .416 \\
$\quad$ Converted VATS to open* & - & - & - \\
Open incision & 1.036 & $0.577-1.860$ & .907 \\
VATS incision & 0.550 & $0.290-1.042$ & .067 \\
FEV $>$ 50\% predicted & 0.955 & $0.463-1.971$ & .902 \\
DLCO $>$ 50\% predicted & 0.573 & $0.367-0.895$ & .021 \\
\hline
\end{tabular}

VATS, Video-assisted thoracoscopic surgery; $F E V_{l}$, forced expiratory volume in 1 second; $D L C O$, diffusing capacity of the lung for carbon monoxide. *Reference category. 
than patients who underwent open lobectomy. Prominent publications describe a low $(1 \%)$ incidence of truly catastrophic intraoperative complications, ${ }^{17}$ yet these may also have the effect of dissuading surgeons comfortable with an open approach from attempting VATS lobectomy. New VATS lobectomy programs may also be concerned by articles recommending performance of 100 or more cases to attain efficiency. ${ }^{18}$

Many centers describe conversion rates for attempted VATS lobectomy ranging from $10 \%$ to $20 \% \cdot{ }^{6,8,19}$ We found that with increasing experience, our conversion rate dropped from $28 \%$ to $11 \%$. Similarly, Gazala and colleagues ${ }^{8}$ noted their conversion rate fell from $15 \%$ to $11 \%$ over a 3 -year period. Highly proficient VATS lobectomy programs are able to safely achieve conversion rates as low as $4 \%{ }^{20,21}$ Whereas several authors have described causes for conversion, ${ }^{19,20}$ these were formalized by Gazala and colleagues $^{8}$ into the parsimonious VALT classification system. Although they described $>40 \%$ of conversions due to vascular causes, the majority $(64 \%)$ of conversions in our cohort were due to anatomy (eg, hilar or pleural adhesions or large tumor size). This is likely related to the nearly $15 \%$ incidence of prior cardiothoracic surgery and $>25 \%$ likelihood of prior granulomatous disease on computed tomography scan in our series. Samson and colleagues ${ }^{6}$ used a computed tomography scan calcification score as a predictor of conversion. Due to the pattern of referrals to our practice, a substantial proportion of radiographic images for our patients were from other facilities and could not be reviewed to assign calcification scores. Instead we used a binary variable of presence or absence of granulomatous disease, signified by intrapulmonary granulomas or mediastinal/hilar lymph node calcification, for our analysis. Although we did not find an association between granulomatous disease and the risk of conversion, it is possible that a dichotomous variable is not sensitive enough to detect a difference. The only variable significant for association with conversion in our study was male gender. No clear biologic explanation for this is available and our finding may be spurious.

The effect of conversion on perioperative morbidity has been variably reported. A study from the United Kingdom ${ }^{9}$ showed no difference in postoperative complications between successful VATS and conversions; however, the data were not reported in a standardized format like the STS database, and hence are harder to interpret. Others have shown a higher incidence of arrhythmias and pulmonary complications, greater estimated blood loss, and a longer length of stay with conversions. ${ }^{6,7}$ This follows general clinical principles and we believe that the comparison group for converted VATS operations should comprise those undergoing a planned open thoracotomy. Our study did not find any difference in either the overall postoperative complication rate or the incidence of specific complications between these 2 groups. Similarly,
Samson and colleagues ${ }^{6}$ noted identical postoperative complications between converted and planned thoracotomy patients with the exception of a slightly higher incidence of atrial arrhythmias in the converted group.

We did not note a difference in long-term survival in patients with pathologic stage I NSCLC who underwent successful VATS lobectomy in comparison to those who were converted or underwent planned open operations on multivariate analysis. Although this was not the focus of our study, others have reported potentially longer survival in patients undergoing VATS lobectomy (compared with open) for clinical stage I NSCLC. ${ }^{22,23}$ The reasons for any potential long-term survival advantage for VATS are unclear. It is possible that a more invasive operation (thoracotomy) may disrupt cancer immune-surveillance to a greater degree or that patients who undergo VATS are better able to tolerate adjuvant treatment if needed. ${ }^{24}$

Limitations to our study include a retrospective design that makes it difficult to control for selection bias in treatment allocation between the open and VATS approaches. Our study also cannot account for variations in practice patterns of individual practitioners, and their level of comfort in proceeding and continuing with a VATS approach in a specific circumstance, although all the surgeons were trained at our own program and have a similar technical approach to pulmonary surgery. Lastly, with the cohort drawn from a single institution, sample size limitations introduce the possibility of type II error, where true differences between groups may not be detected due to sample size constraints. We have tried to avoid misclassification bias in the analysis with 2 reviewers independently analyzing each conversion and a panel discussing any ambiguities. Additionally, with our study, we could not objectively categorize specific cases as unsuitable for VATS lobectomy. However we noted that pulmonary arterial bleeding or hematomas were responsible for the majority of emergent conversions and were much more likely to require transfusion. Hence we have altered our group's practice to electively convert cases where we are experiencing significant difficulty in exposure or dissection of the pulmonary artery.

\section{CONCLUSIONS}

With increasing experience, a high proportion of lobectomy operations can be safely completed thoracoscopically and VATS should be strongly considered as the initial approach for the majority of patients undergoing lobectomy.

\footnotetext{
References

1. McKenna RJ Jr, Houck W, Fuller CB. Video-assisted thoracic surgery lobectomy: experience with 1,100 cases. Ann Thorac Surg. 2006;81:421-5; discussion 425-6.

2. Stephens N, Rice D, Correa A, Hoffstetter W, Mehran R, Roth J, et al. Thoracoscopic lobectomy is associated with improved short-term and equivalent oncological outcomes compared with open lobectomy for clinical Stage I
} 
non-small-cell lung cancer: a propensity-matched analysis of 963 cases. Eur J Cardiothorac Surg. 2014;46:607-13.

3. Swanson SJ, Herndon JE II, D’Amico TA, Demmy TL, McKenna RJ Jr, Green MR, et al. Video-assisted thoracic surgery lobectomy: report of CALGB 39802-a prospective, multi-institution feasibility study. J Clin Oncol. 2007; 25:4993-7.

4. Paul S, Altorki NK, Sheng S, Lee PC, Harpole DH, Onaitis MW, et al. Thoracoscopic lobectomy is associated with lower morbidity than open lobectomy: a propensity-matched analysis from the STS database. J Thorac Cardiovasc Surg. 2010;139:366-78.

5. Ceppa DP, Kosinski AS, Berry MF, Tong BC, Harpole DH, Mitchell JD, et al. Thoracoscopic lobectomy has increasing benefit in patients with poor pulmonary function: a Society of Thoracic Surgeons Database analysis. Ann Surg. 2012;256:487-93.

6. Samson P, Guitron J, Reed MF, Hanseman DJ, Starnes SL. Predictors of conversion to thoracotomy for video-assisted thoracoscopic lobectomy: a retrospective analysis and the influence of computed tomography-based calcification assessment. J Thorac Cardiovasc Surg. 2013;145:1512-8.

7. Sawada S, Komori E, Yamashita M. Evaluation of video-assisted thoracoscopic surgery lobectomy requiring emergency conversion to thoracotomy. Eur J Cardiothorac Surg. 2009:36:487-90.

8. Gazala S, Hunt I, Valji A, Stewart K, Bedard ER. A method of assessing reasons for conversion during video-assisted thoracoscopic lobectomy. Interact Cardiovasc Thorac Surg. 2011;12:962-4.

9. Jones RO, Casali G, Walker WS. Does failed video-assisted lobectomy for lung cancer prejudice immediate and long-term outcomes? Ann Thorac Surg. 2008; 86:235-9.

10. Iedema RA, Jorm C, Long D, Braithwaite J, Travaglia J, Westbrook M. Turning the medical gaze in upon itself: root cause analysis and the investigation of clinical error. Soc Sci Med. 2006;62:1605-15.

11. Cattaneo SM, Park BJ, Wilton AS, Seshan VE, Bains MS, Downey RJ, et al. Use of video-assisted thoracic surgery for lobectomy in the elderly results in fewer complications. Ann Thorac Surg. 2008;85:231-5; discussion 235-6.

12. Villamizar NR, Darrabie MD, Burfeind WR, Petersen RP, Onaitis MW, Toloza E, et al. Thoracoscopic lobectomy is associated with lower morbidity compared with thoracotomy. J Thorac Cardiovasc Surg. 2009;138:419-25.

13. Yendamuri S, Demmy TL. Lobectomy for patients with limited lung function. Semin Thorac Cardiovasc Surg. 2011;23:191-5.

14. Cao C, Manganas C, Ang SC, Yan TD. A meta-analysis of unmatched and matched patients comparing video-assisted thoracoscopic lobectomy and conventional open lobectomy. Ann Cardiothorac Surg. 2012;1:16-23.

15. Yan TD, Black D, Bannon PG, McCaughan BC. Systematic review and metaanalysis of randomized and nonrandomized trials on safety and efficacy of video-assisted thoracic surgery lobectomy for early-stage non-small-cell lung cancer. J Clin Oncol. 2009;27:2553-62.

16. Gopaldas RR, Bakaeen FG, Dao TK, Walsh GL, Swisher SG, Chu D. Video-assisted thoracoscopic versus open thoracotomy lobectomy in a cohort of 13,619 patients. Ann Thorac Surg. 2010;89:1563-70.

17. Flores RM, Ihekweazu U, Dycoco J, Rizk NP, Rusch VW, Bains MS, et al. Videoassisted thoracoscopic surgery (VATS) lobectomy: catastrophic intraoperative complications. J Thorac Cardiovasc Surg. 2011;142:1412-7.

18. Li X, Wang J, Ferguson MK. Competence versus mastery: the time course for developing proficiency in video-assisted thoracoscopic lobectomy. J Thorac Cardiovasc Surg. 2014;147:1150-4.

19. Li Y, Wang J, Yang F, Liu J, Li J, Jiang G, et al. Indications for conversion of thoracoscopic to open thoracotomy in video-assisted thoracoscopic lobectomy. ANZ J Surg. 2012;82:245-50.

20. Villamizar NR, Darrabie M, Hanna J, Onaitis MW, Tong BC, D'Amico TA, et al. Impact of $\mathrm{T}$ status and $\mathrm{N}$ status on perioperative outcomes after thoracoscopic lobectomy for lung cancer. J Thorac Cardiovasc Surg. 2013;145:514-20; discussion $520-1$

21. Park JS, Kim HK, Choi YS, Kim J, Shim YM, Kim K. Unplanned conversion to thoracotomy during video-assisted thoracic surgery lobectomy does not compromise the surgical outcome. World J Surg. 2011;35:590-5.

22. Whitson BA, Groth SS, Duval SJ, Swanson SJ, Maddaus MA. Surgery for early-stage non-small cell lung cancer: a systematic review of the videoassisted thoracoscopic surgery versus thoracotomy approaches to lobectomy. Ann Thorac Surg. 2008;86:2008-16; discussion 2016-8.

23. Chen FF, Zhang D, Wang YL, Xiong B. Video-assisted thoracoscopic surgery lobectomy versus open lobectomy in patients with clinical stage non-small cell lung cancer: a meta-analysis. Eur J Surg Oncol. 2013;39:957-63.
24. Jiang G, Yang F, Li X, Liu J, Li J, Zhao H, et al. Video-assisted thoracoscopic surgery is more favorable than thoracotomy for administration of adjuvant chemotherapy after lobectomy for non-small cell lung cancer. World J Surg Oncol. 2011;9:170.

\section{Discussion}

Dr Thomas A. D'Amico (Durham, $N C$ ). Your study analyzes the rate, etiology, and effect of conversion from attempted thoracoscopic lobectomy to thoracotomy. This study is particularly valuable in that it assesses both emergent and nonemergent conversions and that it employs the standardized root cause analysis using vascular, anatomic, lymph node, and technical etiology. It confirms the findings of other studies, refuting unsupported assumptions to the contrary, that video-assisted thoracoscopic surgery (VATS) conversions have outcomes no worse than planned thoracotomy.

At this time, the term conversion rate has varying meanings and thus must be used carefully. There is a considerable difference between a locally advanced case that may be started thoracoscopically by a surgeon who predicts that the procedure will need to be performed open and converts after a short exploration as opposed to a stage IA case that should be completed thoracoscopically $98 \%$ of the time and yet is converted emergently due to massive bleeding that should have been avoided.

So the value of this study is that it demonstrates not only that conversions do not confer negative outcomes, but also that surgeons need to better predict which cases lead to conversion, to avoid conversions, especially emergent ones. Based on that I have 3 questions for you, and I will ask them individually.

Can you be more specific about the individual VALT (Vascular, Anatomy related, Lymph node, Technical) etiologies? You said that tumor size did not affect conversion, but which vascular complications were more likely to lead to conversion and which lobes were more likely to be converted—what might help a surgeon predict preoperatively by case?

Dr Puri. As far as vascular conversion, $60 \%$ of the vascular injuries were pulmonary artery injuries, $25 \%$ were pulmonary venous injuries, and there were a handful of azygous vein or patent internal mammary artery graft injuries. There were isolated events where small injuries, either the pulmonary artery or pulmonary vein, could be controlled with local pressure and the operation continued thoracoscopically. However, the denominator for vascular injuries was only a handful more than the ones that were converted. So fewer than 10 patients who had recognized vascular injuries had their operations completed thoracoscopically.

As far as lobes are concerned, there was a slight trend toward upper lobes being more involved for both pulmonary arterial as well as pulmonary venous injuries and those injuries requiring conversion. Isolated injuries to either the lower lobe pulmonary artery or pulmonary vein could be controlled, and the operation completed thoracoscopically.

As far as tumor size is concerned, there was no difference between the patients who were converted and those who were not. The difference was actually $6 \mathrm{~mm}$ but it was not statistically significant. But when we look at the anatomy part, the VALT classification, the tumors that actually needed conversion for size were $>8 \mathrm{~cm}$. We did not use a specific logistic regression analysis for that part of the classification because the numbers were relatively small. 
Dr D'Amico. So based on that complete complex analysis, can you better predict conversions now? Are there any cases that should not be even started thoracoscopically?

Dr Puri. At this point in time, all patients in our practice who have central tumors who would either require a pulmonary arterial or a complex bronchoscopic closure are not attempted thoracoscopically. Tumors $>8 \mathrm{~cm}$ in size or tumors that have an infiltrating bronchioloalveolar carcinoma type pattern are not attempted thoracoscopically simply because of difficulty in manipulating the lobe, and the vast majority of tumors converted in this analysis for size reasons were larger than 7 to $8 \mathrm{~cm}$. Also patients with prior pleurodesis are not attempted thoracoscopically at this point in time.

Dr D'Amico. Did you record and analyze the frequency of transfusions? It is known that patients undergoing VATS have fewer transfusions than patients undergoing planned thoracotomies, but what about transfusions for open versus conversions or emergent versus nonemergent conversions?

Dr Puri. The incidence of intraoperative transfusion in our planned open thoracotomy group was just shy of $10 \%$. It was $1.3 \%$ in patients who had their operations completed thoracoscopically and it was $16 \%$ in patients who had conversions. The $16 \%$ rate of transfusions intraoperatively was almost entirely related to vascular injuries, and two-thirds of vascular injuries required intraoperative transfusions, and all of these numbers were statistically significant.

Dr D'Amico. So those cases should have been converted $5 \mathrm{mi}$ nutes earlier?

Dr Puri. I agree with you. I guess the take-home message is: Avoid emergent vascular conversions.

\title{
EDITORIAL COMMENTARY
}

\section{Are we looking at a surgical black box in the future?}

\author{
J. Matthew Reinersman, MD, and Shanda H. Blackmon, MD, MPH
}

See related article on pages 55-62.

During the past 20 years, thoracoscopic lobectomy or video-assisted thoracoscopic surgical (VATS) lobectomy has been established as a feasible and oncologically sound alternative to traditional open lobectomy, and it may be the new criterion standard. Despite current evidence, however, queries of many large national databases continue to demonstrate low overall rates of thoracoscopic lobectomy. Many arguments remain as to why there has not been more widespread adoption of VATS lobectomy. One hurdle may be the perceived risk of catastrophic intraoperative complications and emergency conversions to thoracotomy. Catastrophic complications during VATS lobectomy, are rare, according to Flores and associates. ${ }^{1}$ In their article in this issue of the Journal, Puri and colleagues have now tackled the area of unplanned conversions nicely by examining their institution's experience in the course of 8 years

From the Division of Thoracic Surgery, Mayo Clinic Rochester, Rochester, Minn Disclosures: Authors have nothing to disclose with regard to commercial support. Received for publication Nov 4, 2014; accepted for publication Nov 6, 2014

Address for reprints: Shanda H. Blackmon, MD, MPH, Thoracic Surgery, Mayo Clinic Rochester, 200 First St, SW Rochester, MN 55905 (E-mail: Blackmon.

shanda@mayo.edu).

J Thorac Cardiovasc Surg 2015;149:62-3

$0022-5223 / \$ 36.00$

Copyright (c) 2015 by The American Association for Thoracic Surgery

http://dx.doi.org/10.1016/j.jtcvs.2014.11.016 and more than 1200 operations with thoracoscopic lobectomy and conversions to open thoracotomy. Only a small percentage $(7 \%)$ of their VATS lobectomies required conversion to open thoracotomy.

Puri and colleagues performed a root cause analysis according to a previously published classification system, the VALT system. According to this analysis, $25 \%$ of conversions were related to vascular causes, $64 \%$ related to anatomic considerations, $9 \%$ related to lymph nodes, and $1 \%$ related to technical failure of equipment. The majority of these conversions were nonemergency in nature, and after conversion, patients had similar outcomes to those of planned open lobectomy. Even operations requiring emergency conversion had no worse outcomes other than a higher rate of transfusion. The transfusion rates were greater overall for conversions, but this mostly was related to emergency conversions.

Puri and colleagues found no predictors of conversions. Patients requiring conversion did have a higher clinical $\mathrm{T}$ stage. It does make sense that bulky central tumors are not always approachable through thoracoscopic lobectomy, especially when a larger tumor cannot be removed without spreading the ribs.

A second important finding of this study is the decrease in conversions as experience increased. In this study, during a 3 -year period, the conversion rate fell from $28 \%$ to $11 \%$ as the use of VATS lobectomy increased from $16 \%$ of operations to $76 \%$. Thus with increasing experience a greater proportion of lobectomies can safely be completed by 
TABLE E1. Major perioperative morbidities as defined by the Society of Thoracic Surgeons general thoracic database

Pulmonary

Atelectasis requiring bronchoscopy

Pneumonia

Acute respiratory distress syndrome/respiratory failure

Bronchopleural fistula/empyema

Pulmonary embolus

Initial ventilator support $>48 \mathrm{~h}$

Reintubation

Tracheostomy

Cardiovascular

Atrial arrhythmia requiring treatment

Ventricular arrhythmia requiring treatment

Myocardial infarction

Deep vein thrombosis requiring treatment

Infection

Surgical site infection

Sepsis

Neurology

New central neurologic event

Miscellaneous

New renal failure per RIFLE criteria

Other events requiring operation with general anesthesia

RIFLE, Risk, Injury, Failure, Loss, End-stage kidney disease.

TABLE E2. Comparison of preoperative and postoperative variables in patients undergoing emergent versus nonemergent conversion $(n=87)$

\begin{tabular}{|c|c|c|c|}
\hline Variable & Emergent $(n=20)$ & Nonemergent $(n=67)$ & $P$ value \\
\hline Mean age, $y$ & $63.1 \pm 9.8$ & $64.2 \pm 10.5$ & .674 \\
\hline Male gender & $11(55)$ & $36(54)$ & 1.00 \\
\hline White & $19(95)$ & $54(81)$ & .174 \\
\hline Current smoker & $4(20)$ & $22(33)$ & .126 \\
\hline Prior lung cancer & $2(10)$ & $8(12)$ & 1.00 \\
\hline Mean body mass index & $28.0 \pm 6.1$ & $27.5 \pm 5.7$ & .768 \\
\hline Hypertension & $8(40)$ & $37(55)$ & .309 \\
\hline Granulomatous disease on $\mathrm{CT}$ & $7(35)$ & $16(24)$ & .389 \\
\hline Prior cardiothoracic surgery & $1(5)$ & $12(18)$ & .283 \\
\hline Mean $\mathrm{FEV}_{1}$ percent predicted* & $0.83 \pm 0.21$ & $0.79 \pm 0.18$ & .453 \\
\hline Mean DLCO percent predicted $\dagger$ & $0.68 \pm 0.18$ & $0.70 \pm 0.21$ & .760 \\
\hline Mean length of stay, $d$ & $8.8 \pm 12.3$ & $7.2 \pm 5.1$ & .409 \\
\hline Any postoperative complication & $11(55)$ & $29(43)$ & .446 \\
\hline Pneumonia & $4(20)$ & $7(10)$ & .267 \\
\hline Arrhythmia & $4(20)$ & $12(18)$ & 1.00 \\
\hline Atelectasis & $2(10)$ & $5(8)$ & .658 \\
\hline Air leak $>5 \mathrm{~d}$ & 0 & $2(3)$ & 1.00 \\
\hline Pulmonary embolus & $1(5)$ & $1(2)$ & .409 \\
\hline Respiratory failure & $3(15)$ & $4(6)$ & .344 \\
\hline Reoperation for bleeding & $1(5)$ & 0 & .230 \\
\hline Cerebrovascular accident & $1(5)$ & $1(2)$ & .409 \\
\hline Operative mortality & 0 & $1(2)$ & 1.00 \\
\hline Pathologic stage & & & .798 \\
\hline I & $13(65)$ & $36(54)$ & \\
\hline II & $2(10)$ & $14(21)$ & \\
\hline III & $2(10)$ & $6(9)$ & \\
\hline IV & 0 & $1(2)$ & \\
\hline
\end{tabular}

Values are presented as mean \pm standard deviation or $\mathrm{n}(\%) . C T$, Computed tomography; $F E V_{l}$, forced expiratory volume in 1 second; $D L C O$, diffusing capacity of the lung for carbon monoxide. $* \mathrm{n}=81 . \dagger \mathrm{n}=69$. 